VISION: Journal of Indian Taxation Volume 4, Issue 2, Jul-Dec 2017, pp. 102-111 doi: 10.17492/vision.v4i02.11777

\title{
Awareness and Understanding of GST among Indian Consumers: An Empirical Study
}

\author{
Lovleen Gupta* and Akash Agarwal**
}

\begin{abstract}
The Goods and Services Tax (GST), India's biggest tax reform since Independence emerged as a game changer and seems to be the masterstroke for economic alignment. The $122^{\text {nd }}$ Constitutional amendment made it possible to introduce new tax regime to fix the gaps in the existing system which is estimated to make an incremental growth of $2 \%$ in GDP. In order to investigate the success and effectiveness of the GST, the present research work explores the level of understanding, awareness and acceptance of GST among Indian consumer. Furthermore, the article also investigates the GST effect on spending behaviour of public at large. The primary data was collected from 312 respondents using random sampling from different parts of the country but only 200 responses were found fit for the study. The result shows that consumers, by and large, are acquainted with the GST structure. Moreover, study also reveals that no significant correlation exists between GST tax structure and spending behaviour of respondents.
\end{abstract}

Keywords: Goods and Services Tax (GST); Reliability analysis; Consumer; India.

\subsection{Introduction}

GST is the biggest and substantial indirect tax reform which has taken place in India since Independence. It is not only the tax but also can be called as a reform as it did not only abolish the cascading effect of multiple taxes but also marked as a masterstroke to align the unorganized sector of the economy with the organized sector. On one hand, it increases the revenue collection of both State and Central Government, and on the other, the consumer as the end user anticipates reduction in overall prices due to abolition of multiple taxes in the economic system and manipulating role of middle men.

\footnotetext{
*Corresponding author; Assistant Professor, Department of Commerce, Hindu College, University of Delhi, Delhi, India. (Email id: lovleen15_gupta@yahoo.co.in)

**Assistant Professor, Department of Applied Science, Rajkiye Engineering College, Kannauj,

Uttar Pradesh, India. (Email id: dr.akaskagl@gmail.com)
} 
With $122^{\text {nd }}$ amendment in Constitutional bill, GST replaced the Value Added Tax system (introduced in 2005). GST aims to simplify the entire indirect tax system and intended to make it as identical tax system for everyone. The GST tagline 'one nation, one tax, one market' is self-explanatory. In the process of making it a hot selling cake, Government had made all the efforts to make GST launch a successful show and to create a favourable environment for its implementation and acceptance among public at large. GST as a unified tax mechanism aimed to streamline India's US \$ 2 trillion market economy and estimated to spawn an incremental growth in GDP of about $2 \%$.

GST is a broad consumption tax which had replaced the different indirect taxes such as Value Added Tax System (implemented in 2005), Service Tax, Central Excise and Customs Duty. In order to align Indian market under a single tax system and as one marketplace, the GST was enforced. GST as a domestic trade tax, aimed to serve as an efficient and economic tax system in order to achieve a comprehensive indirect tax mechanism. Being the Multistage Taxation system, it does not only mitigate the cascading and ill effects of large number of Central and State taxes but also make the whole value added system more transparent and effective. India has adopted the Dual GST System, where taxes are levied by both, the central government and the state government the state government levies SGST (State Goods and Service Tax) and central government levies CGST (Central Goods \& Service Tax).

The issue of implementation of GST has been highly debated in various forums and experts had influenced the public at large with their own opinion regarding its pros and cons. Undoubtedly, it caught massive attention from various stakeholder in market including academicians, businessman and consumer at large. Each one of them has their own views and they accordingly explain the aftermath of GST. Among all these personal viewpoints and opinion, there is an absolute felt need for empirical investigation of GST and its effect on the Indian Consumer. The present paper tried to explore the level of understanding, awareness and acceptance regarding GST Structure in India among the Indian consumers. Furthermore, since it is necessary to investigate the impact of GST on spending behaviour of consumer at large. Therefore, the present research work also tried to explore the effect of GST on spending behaviour of consumers.

\subsection{Review of Literature}

There is considerable sparseness regarding the empirical evidence on GST implication in India as it is still only few days old since it was implemented on 01 July 2017. However, the research work available on VAT and similar tax regime structure available in other countries of Asian and South Asian region were analysed for the 
purpose of this study. Most of the articles available on GST in India merely focusing on challenges before the government and traders to adopt and implement the GST tax regime. Furthermore, some articles merely providing the insight about the perceived pros and cons of GST for Indian marketplace.

Auerbach et al. (1983) presented a new simulation methodology for determining the pure efficiency gains from tax reform along the general equilibrium rational expectations growth path of life cycle economies. The principal findings concern the effects of switching from a proportional income tax with rates similar to those in the U.S. to either a proportional tax on consumption or a proportional tax on labour income. It was found in the study that a switch to consumption taxation generates a sustainable welfare gain of almost 2 percent of lifetime resources. A second general result is that even a mild degree of progressivity in the income tax system imposes a very large efficiency cost.

Bollard (1992) examined the New Zealand's experience with consumption tax. It was analysed that introduction of GST has been a major success from a technical point of viewpoint. The tax is well accepted by the business and general public both. The tax is simple to administer because it has a single rate and minimal exemptions. The GST is aimed to enhance revenue by $10 \%$ on an average.

Jain (2016) examined that overcoming the loopholes in the existing indirect tax regime, Goods and services tax (GST) is a major indirect tax reform in India. It was also observed that GST is a nationwide tax levied on supply of goods and services in India. It is a destination based value added tax levied at each stage in supply chain right from the manufacturer to the consumer with benefit of input tax credit at each stage thereby eliminating cascading effects. The final consumer thus will bear only the GST charged by the last dealer in the supply chain. It was concluded that proposed GST regime is expected to bring a basket of benefits for the entire economy thereby favouring its implementation at the earliest by overcoming all the challenges. Proper planning, administration, timely guidance to the industry and training to both the tax officers and payers on GST will aid its smooth implementation.

Gupta (2016) investigated about the principal theoretical issues involved in financial relations between different layers of the government in a federal set up. It looks at the distribution of taxation powers between the Centre and state governments. It also outlines the special provisions with respect to Goods and Services Tax and sharing of Central taxes. The distribution of taxation powers between the Centre and the States is meant to minimise tax problems in a federal set up such as double taxation, tax rivalry among States, duplicate tax administration, and tax evasion. Constitutional division of 
taxation powers between the Union and the States in India rests on economic and administrative considerations. Bollard

Muthupandi and Xavier (2017) in their research article highlighted the importance of imparting awareness and knowledge base regarding GST implementation and its benefit through organization of workshop, training sessions, short term courses etc. Saravanan and Chander Mohan (2017) in their research paper made a comparison of GST with earlier existing Indirect tax regime. The paper evaluated and revealed that GST will cause a negative impact on service sector and manufacturing sector business transaction and positive impact on Intermediary investors and final consumers.

Mohanty and Chandran (2017) analysed that the Goods and Services Tax (GST) has been touted as the single biggest tax reform in the Republic of India. The GST Act proposes to replace all the indirect taxes with a single GST. The profound positive impact of the Act has been reflected in many works in literature. However, the Act has also been criticised for its complex and retrospective nature. The papers focused on GST mainly focused on the brighter side of it and very few of them have provided an allencompassing picture of the Act. The findings highlighted the benefits and concerns related to this Act by taking cues mainly from the write-ups published in the newspapers as well as academic works.

Pabreja (2017) in their study analyse the reaction on GST among public at large in India through 5000 twitter data through sentiment analysis. The study revealed people's acceptance for GST with too much of anticipation feeling.

\subsection{Research Methodology}

The study is based on primary data collected from the respondents from different parts of the country. The Pilot study was conducted to check the reliability, validity and consistency of the questionnaire in addressing the objective. For this purpose, fifty consumers and ten academicians were personally approach in Delhi NCR. Reliability and Validity of questionnaire is established and measured by 'Crohnbach Alpha test'. The questionnaire is having twenty-five close-ended questions based on the Likert Scale. The first eight questions were drafted to explore the understanding of GST among the public at large. The Next eight questions meticulously placed to determine awareness and acceptance of consumers regarding the GST structure. The last nine questions explore the effect of GST on the spending behaviour of consumers and its relationship with the awareness and acceptance level of consumers regarding the same. Random sampling method has been used for sampling purpose. The responses have been 
collected from buyers and sellers available in shopping malls, grocery shops, specialized stores, showrooms etc.

The result of the data is used to determine inclination of consumers at large towards the identified key variable in this study. The study is based on descriptive and correlation analysis and was used to analyse the data collected from the consumers in different parts of the country mostly from cities namely Lucknow, Gorakhpur, Delhi NCR, Hyderabad, Kanpur, Bangalore, Chandigarh and Ahmedabad. Out of 312 questionnaires received, only 200 were found correctly filled and fit for the study purpose. So, the response rate was around $64 \%$ in this study. The descriptive statistics used to elucidate the basic feature regarding the study. It also provides an idea of inclination of consumers towards changes took place in their spending behaviour due to GST. Furthermore, the correlation analysis used to examine the relationship between awareness and acceptance to GST with spending behaviour of consumer in general.

\subsection{Reliability Analysis}

Reliability and validity of Questionnaire is established and measure by 'Cronbach Alpha test'. This test measures the consistency of objectives and the reliability of the responses. In other words, this test is used to measure co-relatedness among the questions in terms of consistency of responses towards a formulated null hypothesis for statistical validation. Actually, this test shows the extent to which all items in questionnaire measure the same characteristic consistently. Reliability is the degree to which measure are free from random errors. Internal consistency reliability is vital to surveys. Internal consistency indicates the extent to which the items are related to each other. The commonly accepted value is 0.70 . It is considered as fairly adequate in view of the fact that the questions are heterogeneous. The results of reliability analysis for pilot and actual study are presented in the Table 1.

Table 1: Reliability Statistics of Each Variable

\begin{tabular}{|l|c|c|}
\hline \multicolumn{1}{|c|}{ Items } & Cronbach Alpha & No. of Items \\
\hline Understanding of GST & 0.729 & 8 \\
\hline $\begin{array}{l}\text { Awareness and Acceptance regarding } \\
\text { GST Structure }\end{array}$ & 0.825 & 8 \\
\hline Effect of GST on Spending Behaviour & 0.864 & 9 \\
\hline Total Question Statement & & 25 \\
\hline
\end{tabular}


Table 1 represents the reliability test statistics for each of the identified variable in the research work. The results shows that for each of the identified variable, the Cronbach's Alpha value is greater than 0.7 which ensure the validity and reliability of the questionnaire response with respect to the research objectives.

The results further indicates that there is a fairly good internal consistency and reliability in the structure and can be used for further analysis (Table 2). It also indicates a fair understanding among the respondents regarding the design of the questionnaire as internal consistency.

Table 2: Results of Reliability Analysis

\begin{tabular}{|l|c|c|c|c|c|c|}
\hline \multicolumn{1}{|c|}{ Items } & $\mathbf{N}$ & $\mathbf{N}$ & $\boldsymbol{\alpha}^{\mathbf{1}}$ & $\begin{array}{c}\text { Internal } \\
\text { consistency }\end{array}$ & $\boldsymbol{\alpha}^{\mathbf{2}}$ & $\begin{array}{c}\text { Internal } \\
\text { consistency }^{2}\end{array}$ \\
\hline Understanding of GST & 8 & 200 & 0.689 & Good & 0.729 & Fairly Good \\
\hline $\begin{array}{l}\text { Awareness and Acceptance of } \\
\text { GST Structure }\end{array}$ & 8 & 200 & 0.714 & Good & 0.825 & Excellent \\
\hline Spending Behaviour & 9 & 200 & 0.726 & Good & 0.864 & Excellent \\
\hline
\end{tabular}

$\alpha=$ Cronbach's Alpha, $\mathrm{N}=$ Number of questions, $\mathrm{n}=$ Number of respondents, ${ }^{1}$ Pilot, ${ }^{2}$ Actual

\subsection{Data Analysis}

\subsection{Understanding of GST}

Table 3 shows the general understanding regarding GST among the respondents. Total eight different set of questions were framed to address these six dimensions of understanding of GST. Based on 5 point Likert scale denoted as "Not understand at all", "Not understand clearly", "Moderately understanding", "Understanding fairly", "Clearly Understanding at all".

Table 3: General Understanding of GST

\begin{tabular}{|l|c|l|}
\hline Components of Level of Understanding & Mean & Level \\
\hline Purpose and objective of GST & 3.24 & Medium \\
\hline Structure and Mechanism of GST & 3.81 & High \\
\hline Rationale for implementation of GST & 3.21 & Medium \\
\hline GST Implication for Economy & 3.28 & Medium \\
\hline Applicability of GST & 2.80 & Medium \\
\hline Popularity of GST & 2.68 & Medium \\
\hline
\end{tabular}


In this highest mean reported by Structure and Mechanism of GST with aggregate mean value of 3.86 which is more than 3.75 and termed high, and lowest mean value with Popularity of GST with aggregate 2.80 as mean value which indicated as medium level of understanding among the population.

\subsection{Awareness and acceptance of GST}

Table 4 depicts the frequency and percentage of specific understanding as awareness and acceptance of GST with further eight questions. It is clearly understood with the responses that most of the respondents have given the expected responses related to standard rated items, exempted supply, zero rated items and types of GST. As much as $72 \%$ to $80 \%$ respondents reported with correct answers. Meanwhile, nearly $28 \%$ respondents are not having clear understanding regarding zero rated items.

Table 4: Awareness and Acceptance of GST Structure

\begin{tabular}{|c|c|c|c|c|c|c|c|c|}
\hline Choices & \multicolumn{2}{|c|}{$\begin{array}{c}\text { Standard Rated } \\
\text { Items }\end{array}$} & \multicolumn{2}{c|}{ Exempted Supply } & \multicolumn{2}{c|}{$\begin{array}{c}\text { Zero Rated } \\
\text { Items }\end{array}$} & \multicolumn{2}{l|}{ Types of GST } \\
\hline $\begin{array}{c}\text { Correct } \\
\text { Answer }\end{array}$ & 161 & $80.5 \%$ & 149 & $74.5 \%$ & 145 & $\begin{array}{c}72.5 \\
\%\end{array}$ & 158 & $79 \%$ \\
\hline $\begin{array}{c}\text { Wrong } \\
\text { Answer }\end{array}$ & 39 & $19.5 \%$ & 51 & $25.5 \%$ & 55 & $\begin{array}{c}27.5 \\
\%\end{array}$ & 42 & $21 \%$ \\
\hline Total & $\mathbf{2 0 0}$ & $\mathbf{1 0 0 \%}$ & $\mathbf{2 0 0}$ & $\mathbf{1 0 0 \%}$ & $\mathbf{2 0 0}$ & $\mathbf{1 0 0 \%}$ & $\mathbf{2 0 0}$ & $\mathbf{1 0 0 \%}$ \\
\hline
\end{tabular}

Source: Primary survey

\subsection{Spending behaviour}

Table 5 represents the nine identified dimensions related to spending behaviours of individuals. The responses have been recorded on standardized five point Likert scale ranging from Strongly Disagree to Strongly Agree. Here the 1 point awarded to Strongly Disagree and 5 point awarded to Strongly Agree response related to specified questions in the questionnaire. The highest mean reported to more purchases in Specified/Unspecified items as 3.82 labelled as 'high' and lowest mean reported to Increased in Price as 2.75 labelled as Medium. Furthermore, it has been interesting to witness that respondents report that applicability of GST has adversely affected their mood for eating outside in some specified restaurants and they used to avoid paying taxes as the mean value reported is 3.75 which is labelled as 'High'. 
Table 5: Effect on Spending Behaviour of Respondents

\begin{tabular}{|l|c|c|}
\hline \multicolumn{1}{|c|}{ Components of Spending Behaviour } & Mean & Level \\
\hline Do you think about GST before spending & 3.23 & Medium \\
\hline Affecting purchasing power negatively & 3.26 & Medium \\
\hline Adversely affecting eating outside & 3.75 & High \\
\hline Avoiding to pay taxes & 3.75 & High \\
\hline Increase price & 2.75 & Medium \\
\hline Effect on Spending pattern & 3.26 & Medium \\
\hline More purchases in specific items & 3.82 & High \\
\hline Reduce frequency of visiting shopping malls & 3.64 & Medium \\
\hline $\begin{array}{l}\text { Negatively affecting purchasing of standard-rated } \\
\text { items }\end{array}$ & 3.56 & Medium \\
\hline
\end{tabular}

\subsection{Relationship between awareness and spending behaviour}

Table 6 as shown in appendix depicts correlation exists between Awareness \& Acceptance of GST with Spending behaviour of respondents. The reported value of correlation coefficient is +0.03 which shows that there are no significant relationships between level of awareness of GST on spending behaviour. It can further inferred as GST Rate structure have not made any significant effect on the spending behaviour of respondent in specific and public at large in general.

Table 6: Results of Correlation Analysis

\begin{tabular}{|l|c|c|}
\hline & Awareness and Acceptance of GST & $\begin{array}{c}\text { Spending Behaviour of } \\
\text { Respondents' }\end{array}$ \\
\hline Correlation Coefficient & 1.000 & .030 \\
\hline Sig. (2-tailed) & .000 & .603 \\
\hline $\mathrm{N}$ & 200 & 200 \\
\hline Correlation Coefficient & .030 & 1.000 \\
\hline Sig. (2-tailed) & .603 &. \\
\hline $\mathrm{N}$ & 200 & 200 \\
\hline
\end{tabular}

\subsection{Conclusion}

GST regime in India is just few days old and all the stakeholders especially the consumers of the country are yet to get the true flavour of this hot selling cake. The present research article makes a fair attempt to study the relationship between GST tax 
structure and its effect on spending behaviour of consumers. The research work further makes an effort to explore the awareness and adaptability regarding the GST system. Since there was a scanty of empirical evidence with special reference to India due to obvious reason, the present research work can serve as a base for further studies in this regard. With the present research work the researcher has been able to contribute in this area with some important findings. Firstly, the respondents were somewhat aware about the GST system and its introduction in India but it was observed that people are yet to get more awareness about the different aspect of it. As India had adopted the dual GST system, it has hot its own complexities and many stakeholders including businessman, suppliers, wholesalers' and retailers are yet to get accustomed to its functionality and input tax credit system. As per the study, $75 \%$ of the respondents were having the awareness about the GST and its applicability. Furthermore, the study also reveals that although most of respondents avoid paying tax but there is no clear correlation exists with GST structure and their spending behaviour. It further implied that GST structure did not make any significant effect on the spending pattern of the respondents in general.

\section{References:}

Auerbach, A. J., Laurence J. K. \&, Jonathan, S. (1983). The efficiency gains from dynamic tax reform. International Economic Review, 24(1), 81-100.

Bollard, A.E. (1992). New Zealand's experience with consumption tax. New Zealand Institute of Economic Research Working Paper 92/1.

Gupta, S. (2016). Goods and services tax (GST): A comprehensive and uniform indirect tax reform in India. VISION: Journal of Indian Taxation, 3(2), 31-53.

Jain, S. (2016). Constitutional provisions pertaining to taxes and its implication for GST. VISION: Journal of Indian Taxation, 3(2), 54-80.

Mohanty, P. \&, Chandran, A. (2017). GST and the paradigm shift: A peripheral view. VISION: Journal of Indian Taxation, 4(1), 51-67.

Muthupandi, S. \&, Xavier, A.J. (2017). Awareness of implementation of goods and services tax (GST) among college students' in Sivakasi. International Journal of Engineering Science and Computing, 7(4), 01-06. 
Pabreja, K. (2017). GST sentiment analysis using twitter data. International Journal of Applied Research, 3(7), 660-662.

Saravanan, S. \&, Chander Mohan, K. (2017). Assessment and impact of existing indirect tax to goods and service tax in India. International Journal of Scientific Research in Computer Science, Engineering \& Information Technology, 2(3), 623-629. 